\title{
Exaggerated displacement of the atrioventricular canal towards the bulbus cordis (rightward displacement of the mitral valve)
}

\author{
M. Quero Jiménez, V. M. Pérez Martínez, M. J. Maitre Azcárate, \\ G. Merino Batres, and F. Moreno Granados \\ From Servicio de Cardiología Pediátrica, Clinica Infantil 'La Paz', Madrid, Spain
}

Seven malformed hearts in which a common feature seems to be an exaggerated displacement of the atrioventricular canal towards the bulbus cordis, i.e. the future right ventricle, are described. Transposition or malposition of the great arteries and a ventricular septal defect existed in 6 patients. Certain comparisons are established between previously described entities with which these cases have a clear connexion. The material has been divided into 3 basic groups according to the total or partial grade of the atrioventricular canal displacement towards the bulbus cordis, and to the sequence with which the papillary muscles are missing from the rest of the left ventricle. The comparative size of both ventricles is studied in relation to the total area of the atrioventricular canal, which both receive. Attention is called to the frequency with which, in these cases, there was a D-bulbo-ventricular loop and a double outlet right ventricle with a bilateral subpulmonary and subaortic muscular conus. Stress is laid on the importance of the coronary distribution which surrounds the small left ventricle at the time of dissection and its internal examination. The systematic anatomical and clinical study led to an appreciation of the importance of angiocardiography with respect to the diagnosis.

In 1968, De la Cruz and Miller established the homology between the single left ventricle (Van Praagh, Ongley, and Swan, 1964) and the double inlet left ventricle. Later, Muñoz Castellanos et al. (1969) described a case which they called, 'double inlet and double outlet right ventricle'. Latterly (Scientific Council on Pediatric Cardiology, 1970) the term, single right ventricle, was made synonymous with that of double inlet right ventricle. In 1971, Liberthson et al. reported a study of a wide series of malformations in which the portion of the atrioventricular canal destined to be the tricuspid orifice presented various grades of displacement towards the left ventricle.

The intention here is to present a study of 7 cases in which the future mitral orifice suffered either a major or minor displacement towards the right ventricle. We believe that these cases are similar to that studied by Muñoz Castellanos et al. (1969), and we wonder if the final outcome, with the future mitral orifice totally displaced towards the right ventricle, does not correspond to what Van Praagh et al. (I964) described as the single right ventricle and which Received 26 June 1972. later became synonymous with the term double inlet right ventricle (Scientific Council on Pediatric Cardiology, 1970).

\section{Subjects and methods}

Of the 7 cases studied, 6 were confirmed at necropsy, and in one, included in group $B$ because of the size of the left ventricle, the diagnosis was based on cardiac catheterization and angiocardiographic findings (Fig. I).

A routine cardiological study with plain chest films and electrocardiograms was carried out in all cases. A haemodynamic and angiocardiographic study was done in 3 cases.

The cases have been divided into groups (Table) according to the grade of displacement of the atrioventricular canal towards the bulbus cordis, and in accordance with the sequence in which the papillary muscles were absent from the left ventricle, a cavity that was always present. Thus, we have group A characterized by a total displacement of the atrioventricular canal towards the bulbus cordis ( 2 cases) and defined by the total absence of the papillary muscles of the left ventricle.

Group B (3 cases) in which we detected a left ventricular cavity in which there was only the posterior group of papillary muscles and in which the transfer- 


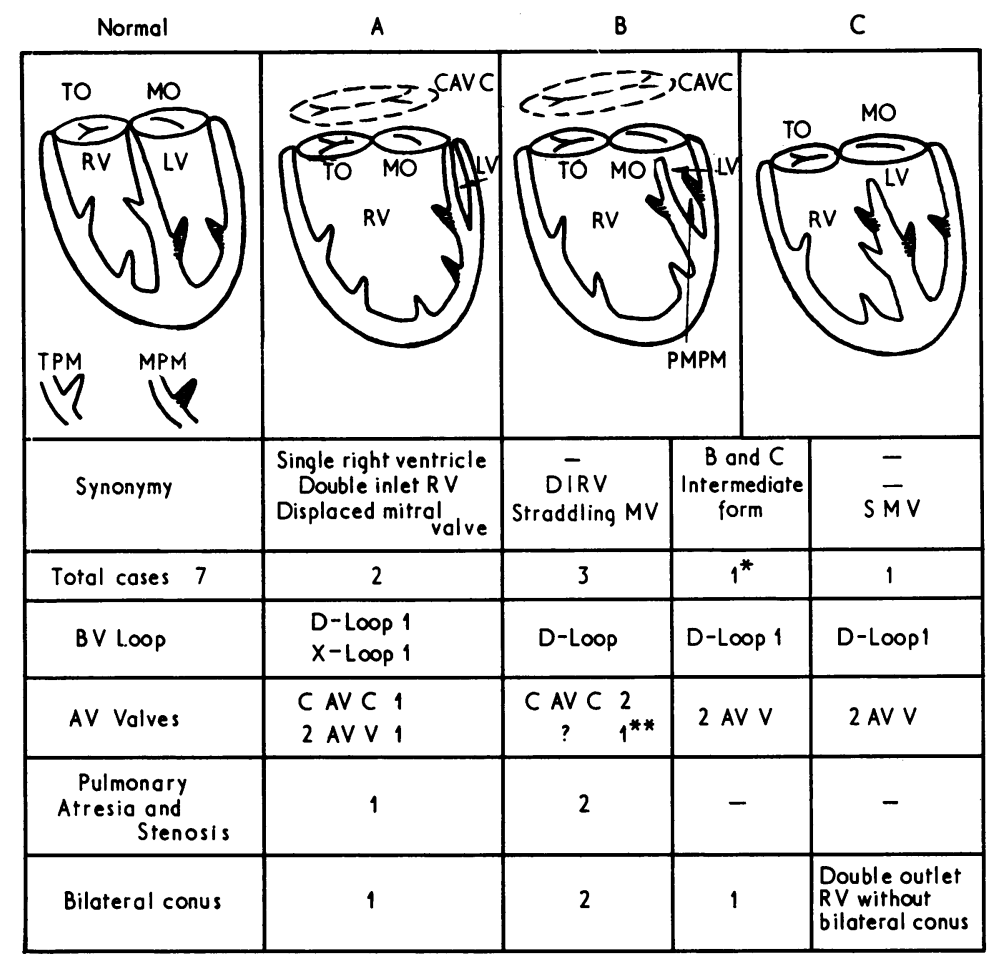

FIG. I Terminology, classification, and distribution of the cases. In the first column the most salient characteristics of a normal heart are summarized. The tricuspid orifice (TO) is received by the right ventricle $(R V)$, the mitral orifice $(M O)$ entering the left ventricular cavity $(L V)$. The normal number of papillary muscles is present in each ventricle. The 3 papillary muscles normally present in the right ventricle (TPM) are unshaded and the 2 of the left ventricle (MPM) shaded.

In the second column are the most important features of group $A$ cases. The atrioventricular canal, common (dotted ring, CAVC) or divided in the mitral (MO) and tricuspid (TO) orifices, is completely received by the right ventricle $(R V)$. The left ventricle $(L V)$ is hypoplastic and completely deprived of its normal papillary muscles. The terms single right ventricle, double inlet right ventricle, and displaced mitral valve could be applied to such cases.

The third column illustrates the defining features of the group $B$ cases. The right ventricle $(R V)$ receives the major part of the atrioventricular canal, common (dotted ring, CAVC) or divided in the mitral (MO) and tricuspid (TO) orifices. Since the left ventricle receives part of the mitral orifice (MO), it is better developed than in the group $A$ cases, and it contains the posterior group of papillary muscles (PMPM).

The fourth column illustrates the features of the Group $C$ case. The right ventricle receives the tricuspid orifice (TO) and a small area of the mitral orifice (MO). The left ventricle $(L V)$, receiving the larger portion of the mitral orifice $(M O)$, is better developed than in the previous groups, and it contains its 2 normal groups of papillary muscles. The term straddling mitral valve could be applied to the group $B$ and $C$ cases.

Certain important anatomical characteristics of the 3 groups have been recorded below in the particular columns, the ones pertaining to the special case (Fig. 2) being placed between those corresponding to groups $B$ and $C$ cases. Other abbreviations: DIRV, double inlet right ventricle; $M V$, mitral valve; SMV, straddling mitral valve; $A V V$, atrioventricular valve.

$I^{\star}$ : This case, described elsewhere in the paper under the title of 'special case' has anatomical features intermediate between the group $B$ and $C$ cases.

$I^{\star \star}$ : This case has been diagnosed angiocardiographically, the common or divided nature of the atrioventricular canal remaining undetermined. 
TABLE

\begin{tabular}{llllll}
\hline Case & Group & Age & Sex & $\begin{array}{c}\text { Heart } \\
\text { failure }\end{array}$ & Cyanosis \\
\hline Case I & A & 4 mth & F & + & \pm \\
Case 2 & A & 22 dy & M & & +++ \\
Case 3 & B & I5 dy & F & +++ & \\
Case 4 & B & 3 mth & F & & +++ \\
Case 5 & B* & 2 mth & M & & + \\
& & still alive & & & + \\
Case 6 & C & 3 dy & M & ++ & + \\
Case 7 & SCt & I mth & M & +++ & \pm \\
& & & & & \\
\hline
\end{tabular}

* Angiocardiographically diagnosed.

+ Special case.

ence of the atrioventricular canal towards the bulbus cordis was not so exaggerated as in group $\mathrm{A}$, the mitral valve partly overriding the left ventricle.

Group C consists of only I case characterized by the existence of 2 groups of papillary muscles, anterior and posterior, and a well-developed left ventricle. The mitral orifice, however, overrode the ventricular septum pushing through a third papillary muscle into the right ventricle. A special intermediate case existed between groups $B$ and $C$ (Fig. 2) characterized by the possession of a large left ventricle, as in group $C$, but only a posterior group of papillary muscles, as in group B. In general,

FIG. 2 Schematic illustration of the 'special case' (Case 7). Note the larger size of the left ventricle $(L V)$ as compared with the right one $(R V)$, in spite of the fact that this latter cavity receives the tricuspid valve $(T V)$ and part of the mitral one (MV).

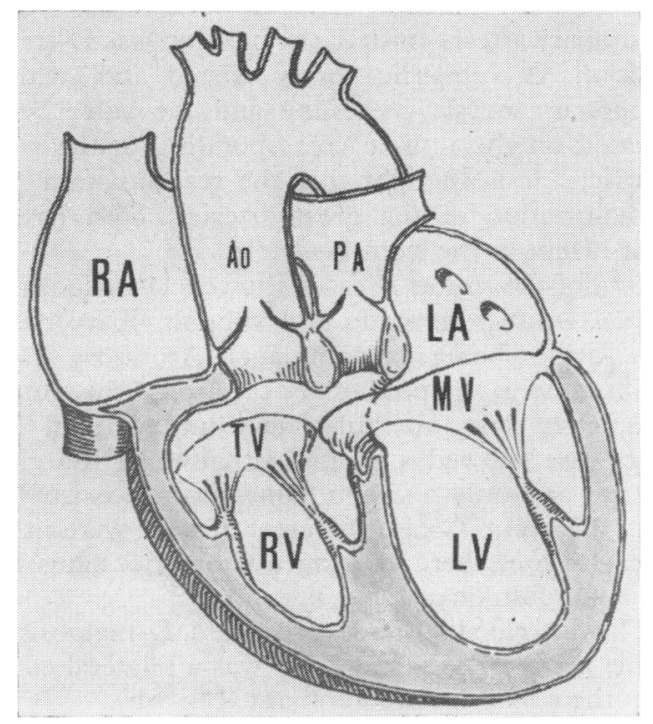

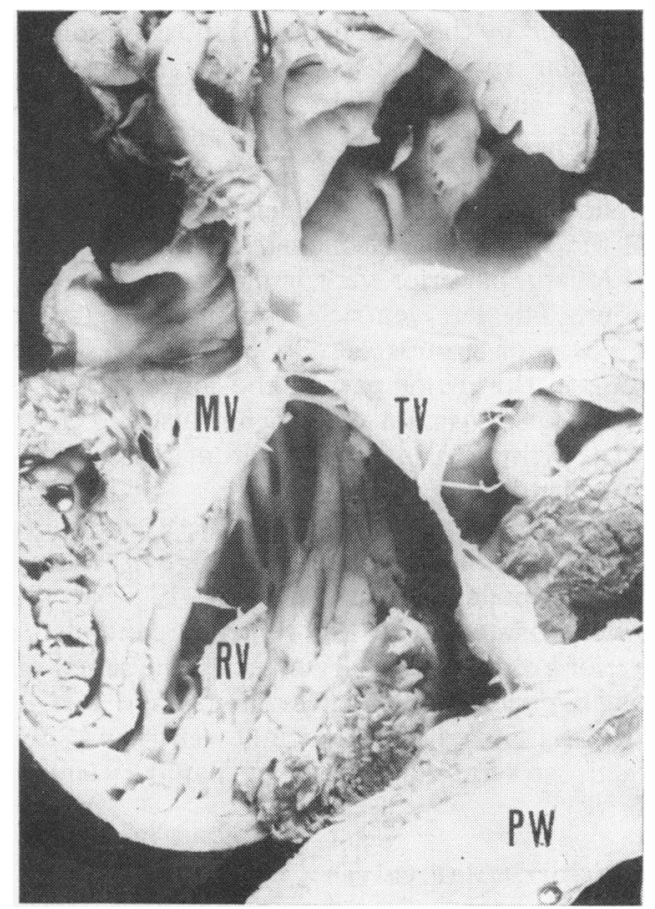

FIG. 3 Internal view of the right ventricle of a group $A$ case viewed from behind. The right ventricular cavity $(R V)$ receives both the mitral $(M V)$ and tricuspid $(T V)$ valves. $P W$, posterior wall of the right ventricle.

with the exception of this case, the size of the left ventricle was very small in group A, small in group B, and normal in group $\mathrm{C}$.

\section{Anatomical findings \\ Ventricles}

Both cases in group A possessed a very large right ventricle, which supported the complete valvular and subvalvular apparatus (Fig. 3) and a small clearly hypoplastic left ventricle in which there were no traces of either valvular or subvalvular remains (Fig. 4). In one case there was a ventricular septal defect, partially covered by the left portion of a common atrioventricular valve, which was inserting itself into the top rim of the defective ventricular septum. In the other case no traces of a ventricular septal defect could be found.

In group B only 2 of the 3 cases had anatomical verification, the common characteristic of these 2 being the existence of a large right ventricle and a small left ventricle, less hypoplastic than in the group $\mathrm{A}$ cases and which, in addition, possessed part of the valvular and subvalvular apparatus 
represented by the left portion of the common atrioventricular valve and by the posterior group of papillary muscles which existed in both cases (Fig. 5).

What characterized the group C case was the presence of a normal-sized left ventricle (Fig. 6a) with the right ventricle being slightly bigger (Fig. 6b). A large anterior ventricular septal defect was present. The left ventricle contained the anterior and posterior groups of papillary muscles, and it supported the major part of the mitral valve (Fig. 6a), part of the septal valve being inserted directly into the right part of the top rim of the septum by fibrous bands (Fig. 6b).

In the special intermediate case between groups $B$ and $\mathrm{C}$ (Fig. 2) the right ventricle (Fig. 7 b) was paradoxically smaller than the left one (Fig. 7a) which was very dilated. The left ventricle contained the posterior group of papillary muscles, the septal valve having overridden the ventricular septal defect (Fig. 7a) to be inserted into the right ventricular cavity through an anterior group of papillary muscles (Fig. 7b).

\section{Atrioventricular valves}

In group $\mathrm{A}$, one of the cases had a common atrioventricular valve which joined both atria with the right ventricle. In the other case, 2 well-developed atrioventricular valves existed, both of which led to the right ventricle (Fig. 3). The posterior leaflet of the mitral valve formed something like a small roof over the rest of the left ventricle, possibly closing the ventricular septal defect which, in this case, could not be found (Fig. 4).

In both the group B cases, studied anatomically, a common atrioventricular valve was found to exist. In the group $\mathrm{C}$ case, 2 atrioventricular valves existed with the septal leaflet of the mitral valve, overriding the ventricular septum (Fig. $6 \mathrm{a}$ and $6 \mathrm{~b}$ ). In the case intermediate between groups $B$ and $C, 2$ atrioventricular valves existed, the mitral one being much bigger than the possibly stenotic tricuspid, to such a degree that the mitral portion which was received by the left ventricle was larger than the total tricuspid and mitral valvular area received by the right ventricle (Fig. 2, 7a, and 7 b).

\section{Bulboventricular loop}

In group A one case had an indeterminate bulboventricular loop, and the other a D-loop. The other cases in the remaining groups all had D-loops.

\section{Position of great arteries}

In the group $\mathrm{A}$ case with an indeterminate bulboventricular loop, there also existed an L- malposition of the great arteries with a bilateral conus

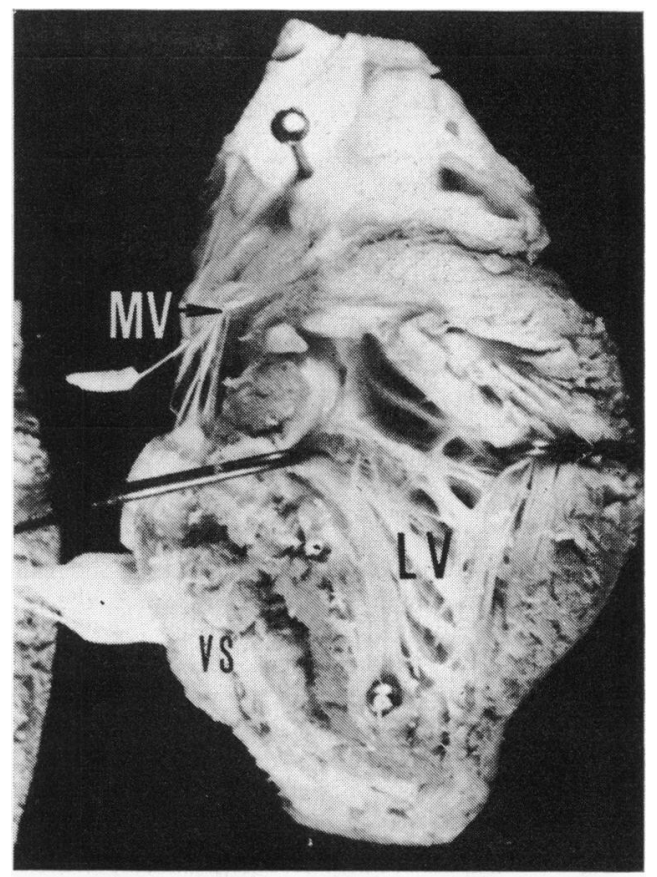

FI G. 4 Close-up view of the interior of remaining left ventricular cavity ( $L V)$ of the same case as Fig. 3. This cavity has been isolated in a portion of the posterior wall of the apparently single right ventricle (see Fig. 3). There are neither papillary muscles nor chordae. The posterior portion of the left atrioventricular valve (MV) overlaps the ventricular septum (VS) to become inserted into the right part of the top rim of it $(V S)$.

predominantly subaortic. In the other case where pulmonary atresia existed, the position was D-transposition. A subaortic conus existed and, with a pulmonary atresia coexisting and the valve being situated on the muscle corresponding to the right ventricle, it is thought that the real situation was D-malposition of the great arteries, both having their origin in the right ventricle.

One of the group B cases showed D-malposition with a double subaortic and subpulmonary conus (the former being predominant). Accessory tissue was located in the pulmonary conus and this almost completely closed the pulmonary outflow tract. The other case showed a normal situation of the great arteries and only a subpulmonary conus existed.

In the group $C$ case the great arteries were in Dtransposition, there existing a subaortic conus but not a subpulmonary one (Fig. 6b).

The intermediate case presented D-malposition of the great arteries and there was a bilateral conus with the subaortic predominant (Fig. 7b). 


\section{Associated lesions}

All the cases except one had a ventricular septal defect. The first case in group A (Case I, Table) was one of asplenia with the lungs bilaterally trilobated, infradiaphragmatic total anomalous pulmonary venous return to the portal system, double superior vena cava, and a persistent ductus arteriosus. The second case in this group was associated with pulmonary atresia (Case 2, Table). In Group B, the second case (Case 4, Table) had pulmonary stenosis and a long narrow duct. The first case (Case 3, Table) showed hypoplasia of the aortic isthmus.

The case in group C (Case 6, Table) presented no associated lesions and the special case (Case 7, Table) showed hypoplasia of the aortic isthmus and a persistent duct.

\section{Bedside findings}

The age of the patients ranged between 3 days and 4 months (Table). Except for one case aged 20 months and who is still alive, the remainder have all died prematurely, the age at death ranging between 15 days and 5 months.

The bedside findings were not characteristic and the cases were either diagnosed as cardiopathies with cyanosis and pulmonary plethora or with cyanosis and pulmonary ischaemia, according to the state of the pulmonary outflow tract. The former group consisted of Cases $I, 3,6$, and 7, and the latter group consisted of the remaining cases.

The characteristics of the former group were severe cardiac insufficiency and slight cyanosis, those of the latter group being predominant cyanosis with no signs of heart failure.

\section{Radiological findings}

They were not characteristic and chiefly depended upon the degree of patency of the pulmonary outflow tract.

The heart and other viscera were placed normally in every case except for one in group $A$, which showed heterotaxia.

Heart enlargement was found in 3 cases without pulmonary stenosis. A normal heart size was encountered in the remaining case without pulmonary stenosis and in the 3 cases with pulmonary outflow obstruction.

The lung fields were clear in the 2 patients with pulmonary atresia. In 2 cases - one with pulmonary stenosis and the other with an unobstructed pulmonary outflow tract - the lung fields appeared to be normal. In the remaining 3 cases without pulmonary stenosis, the pulmonary circulation was greatly increased.

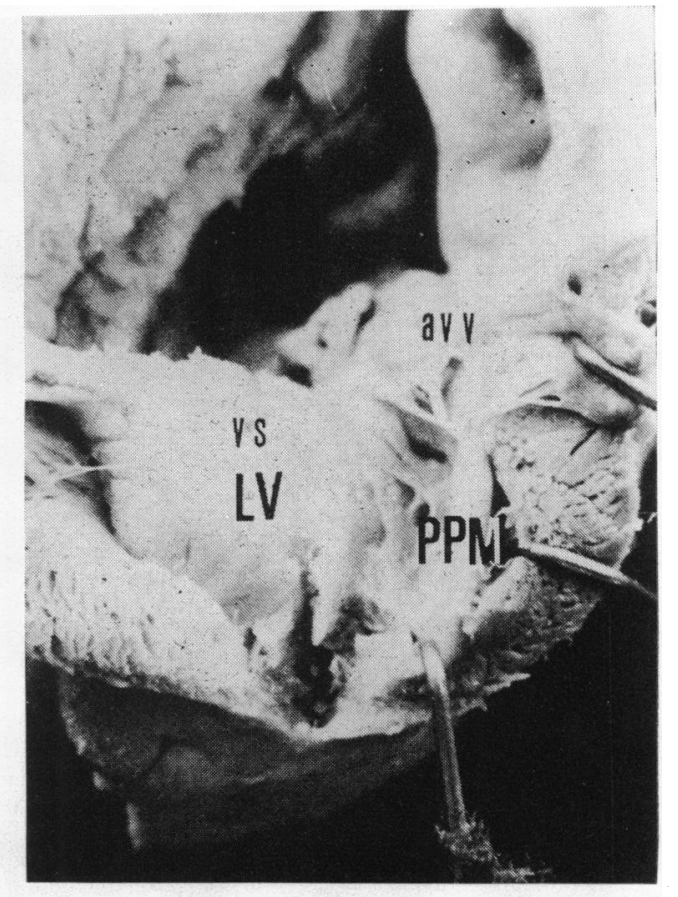

FIG. 5 Internal view of the remaining left ventricle $(L V)$ of a group $B$ case. The small area of the common atrioventricular valve $(A V V)$ is received by a posterior papillary muscle (PPM), the only one present in the left ventricular cavity. VS, ventricular septum.

The pulmonary arch was absent in 2 cases, with a severely obstructed pulmonary outlet, and prominent in 2, with increased pulmonary blood flow. The aorta was larger than normal in the 2 cases with a greatly diminished pulmonary circulation. Enlargements of the right chambers was seen in 3 patients with increased pulmonary blood flow. A left superior mediastinal border suggesting a left superior vena cava, afterwards proved at necropsy, was seen in a patient with diminished pulmonary blood flow. 'Coeur en Sabot' was encountered in one case with severe pulmonary outflow obstruction.

In summary, therefore, the radiological findings were not characteristic and did not differ very much from those encountered in other complex forms of congenital heart diseases with intracardiac mixing and augmented or diminished pulmonary circulation.

\section{Electrocardiographic findings}

Sinus rhythm was found in every case. Right atrial enlargement was found in 2 cases belonging to group $B$ and in the special case. The QRS axis was 


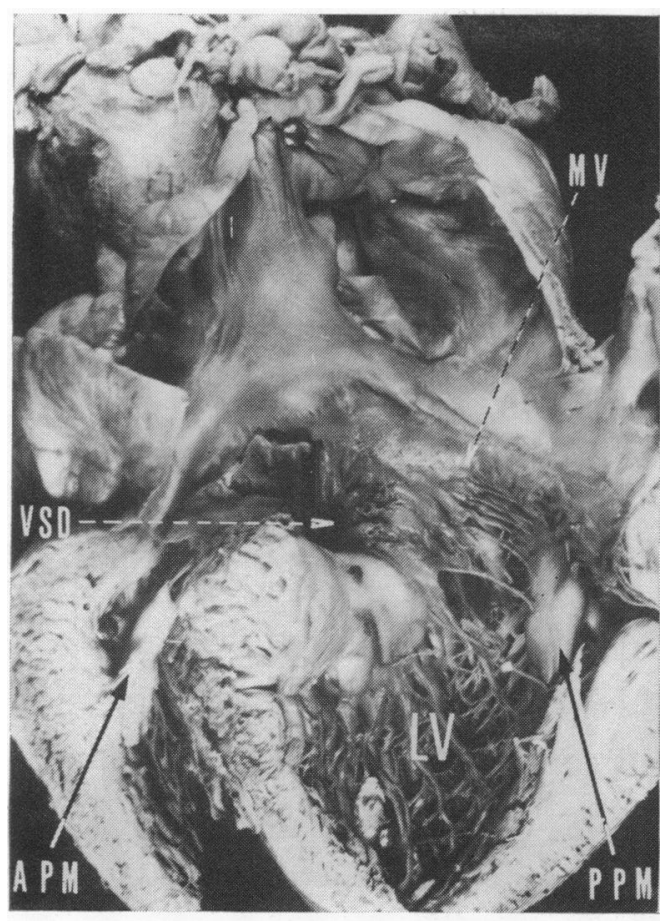

A

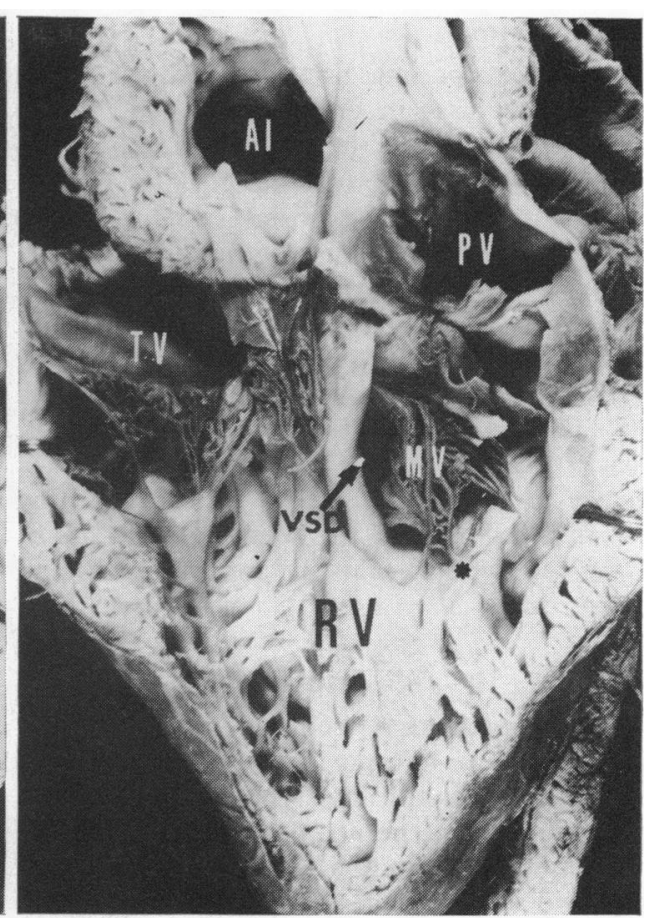

B

FI G. 6 (A) Interval view of the left ventricle $(L V)$ in a Group $C$ case. The mitral valve $(M V)$ is partly received by 2 groups of papillary muscles situated in the left ventricular cavity. The valve overlaps the ventricular septum (VS) passing through a ventricular septal defect (VSD). $(B)$ internal view of the right ventricle $(R V)$ of the same case. Part of the mitral valve $(M V)$ enters the right ventricle through the ventricular septal defect $(V S D)$ to be received by short chordae $(+)$ situated in the right part of the top rim of the ventricular septum (VS). APM, anterior papillary muscle; PPM, posterior papillary muscle; TV, tricuspid valve; $A I$, aortic infundibulum; PV, pulmonary valve.

indeterminate in the case belonging to group C. In 2 cases with a common atrioventricular valve, the QRS axis was directed upwards. In the remaining 4 cases, the $Q R S$ axis ranged between $+120^{\circ}$ and $+180^{\circ}$.

Electrocardiographic signs of right ventricular enlargement were present in all the cases belonging to groups A and B. In the case included in group C, and in the 'special case', a pattern of biventricular hypertrophy was found. Thus, the pattern of ventricular hypertrophy correlated fairly well with the ventricular size encountered at necropsy.

\section{Cardiac catheterization and angiocardiography}

Only in Cases I, 5, and 7 (Table) were these investigations performed. In all 3 the aorta was entered from the right ventricle. In Cases I and 7, the pulmonary artery, also catheterized from the right ven- tricle, showed a systemic pressure. The $\mathrm{O}_{2}$ saturations in the right ventricle were higher than in the right atrium in the 3 cases.

Angiocardiography, with contrast injection into the right ventricle, was performed in these 3 cases. In each one a double subaortic and subpulmonary infundibulum could be seen (Fig. 8). In Cases I and 5 , the lateral projection showed a greatly enlarged right ventricle and a very tiny, posteriorly situated left ventricular cavity (Fig. 8). In Case 7, the left ventricle was far larger than the right one. Mitral atresia was ruled out in Case 5 by making an injection of contrast material in the left atrium.

\section{Discussion}

The most important points found in our 7 cases of exaggerated displacement of the atrioventricular canal towards the bulbus cordis are outlined here.

In the first phases of the development of the em- 

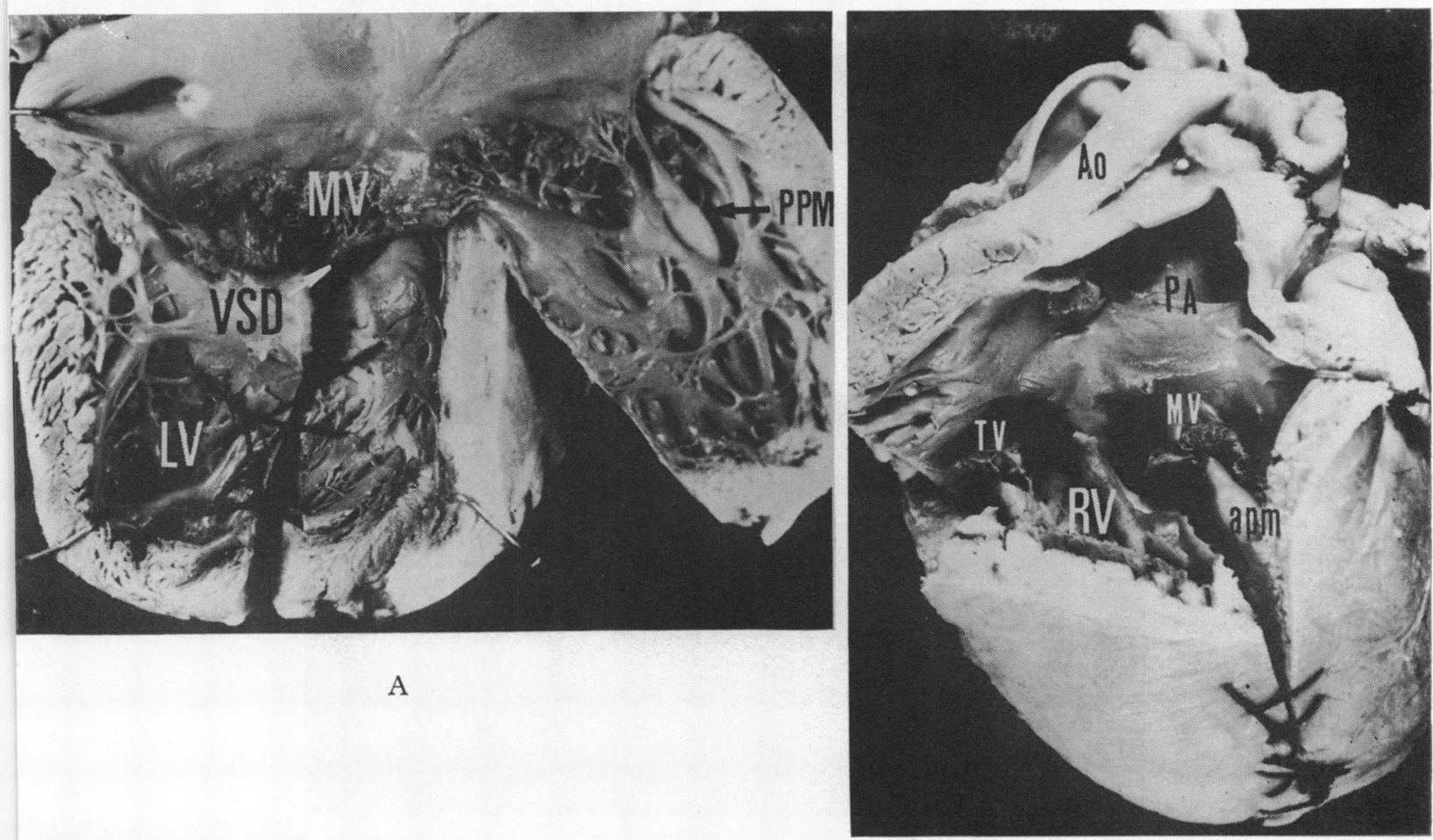

A

B

FIG. 7 (A) Internal view of the left ventricular cavity $(L V)$ in the special case. Notice the large size of this ventricle compared with the right one (see $B)$. The anterior leaflet of the mitral valve $(M V)$ straddles the ventricular septum $(V S)$ entering the right ventricle through a large ventricular septal defect (VSD) occupying the entire upper portion of the ventricular septum. There is a lack of the anterior group of papillary muscles. PPM, posterior papillary muscle. (B) Internal view of the right ventricle of the same case. In spite of the fact that this cavity is receiving the tricuspid orifice (TV) and part of the mitral valve $(M V)$, its size is clearly inferior to that of the left ventricle (see $A) . R V$, right ventricle; $P A$, pulmonary artery; Ao, aorta; apm, anterior papillary muscle.

bryo, the common atrioventricular canal is connected to the primitive ventricle (De la Cruz and Miller, I968) and only through this chamber and the bulboventricular foramen can the blood reach the bulbus cordis. The XIIIth Streeter horizon is where the movement of the common atrioventricular canal towards the bulbus cordis begins in order to connect up with it (De la Cruz and Miller, 1968). This movement reaches its completion towards the XVIth Streeter horizon. Apparently, it is at this point that the following phenomena begin: (A) The division of the common atrioventricular canal into 2 separate orifices by the growth of the dorsal and ventral endocardial cushions; (B) the formation of the right ventricle from the bulbus cordis (De la Cruz and Miller, 1968). When the movement of the common atrioventricular canal towards the bulbus cordis does not proceed in this way, a wide spectrum of heart malformations arises. The malformations, in which there has been a complete or partial arrest in the normal displacement of the atrioventricular canal towards the bulbus cordis, would be situated at one end of this spectrum. The names of single ventricle with a rudimentary outlet chamber, single (primitive) ventricle (Lev et al., I969), single left ventricle (Van Praagh et al., 1964), double inlet left ventricle (De la Cruz and Miller, 1968), displaced and straddling tricuspid valves and orifices (Liberthson et al., 1971), etc., have been used for these heart malformations. The group of malformations, in which there has been an exaggerated displacement of the atrioventricular canal towards the bulbus cordis, would be situated at the other end of this spectrum. These last cases have received little atten- 


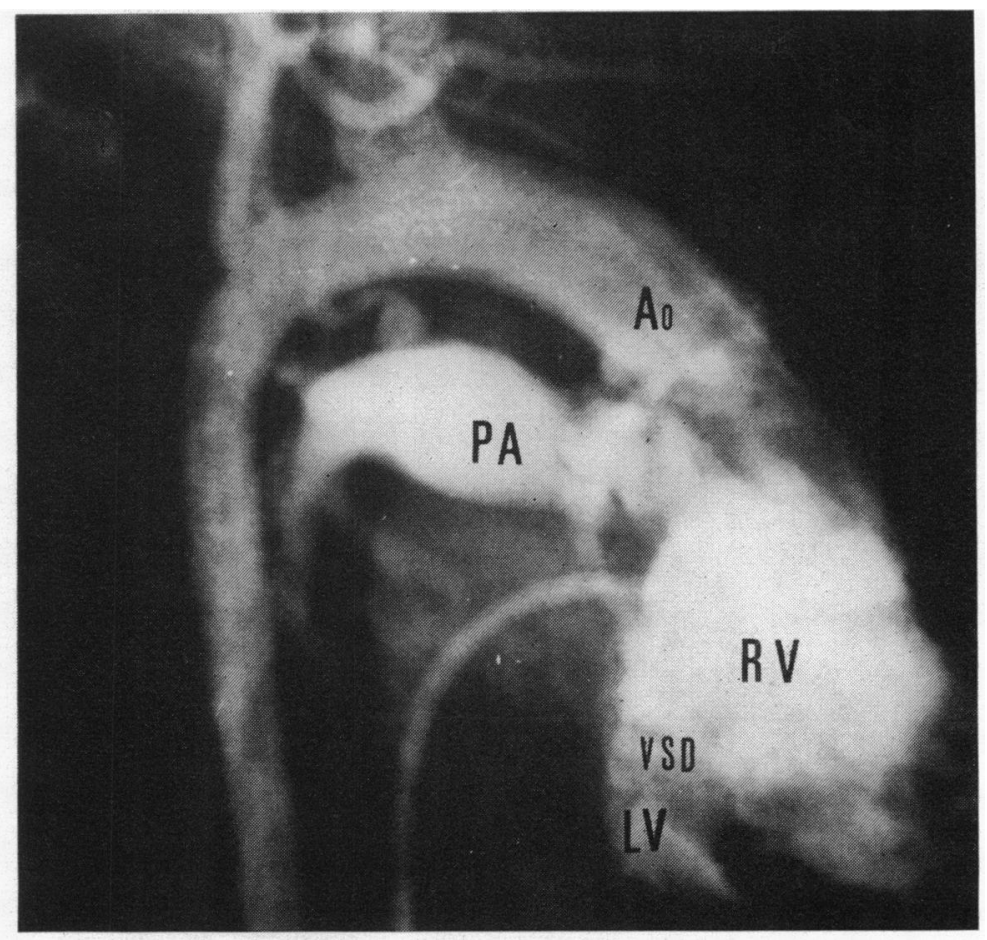

FIG. 8 Lateral projection of a right ventricular angiocardiogram (Case I, Table). Both great arteries, the aorta $(A o)$ and the pulmonary artery $(P A)$, are supported by an infundibulum and have their origin in a large right ventricle $(R V)$. The hypoplastic left ventricle $(L V)$ which is situated behind the right one $(R V)$ has filled with contrast material coming from the right ventricle through a ventricular septal defect (VSD).

tion and the only similar contribution that we have found in reviewing the published reports on them have been the specimens reported by Van Praagh et al. (1964) with the names of single right ventricle, and the report by Muñoz Castellanos et al. (1969) of double inlet and double outlet right ventricle. Curiously enough, the two terms of single right ventricle were made synonymous in 1970 (Scientific Council on Pediatric Cardiology).

As has been previously shown in this paper, our cases have been distributed among groups according to the degree with which the exaggerated movement of the atrioventricular canal towards the bulbus cordis had taken place, the degree of left ventricular hypoplasia, and the sequence in which this cavity lost its papillary muscles (Fig. I).

In group $\mathbf{A}$ we have included 2 cases with a very small left ventricle in which no traces of papillary muscles could be found. Our Case 2 (Table, Fig. 3 and 4), with ventricular septum intact, can be considered exactly the same as the specimens reported by Van Praagh et al. (1964) with the name of single right ventricle. Nevertheless, we are reporting, in this paper, for the first time, the discovery of the hypoplastic left ventricle in these cases (Fig. 4). Establishing a parallel with the terminology used by Liberthson et al. (I97I) for the tricuspid orifice, the name of displaced mitral valve would be quite adequate for these cases. Similarly, the term of straddling mitral orifice would be fairly appropriate for our group B cases.

The other group A case with a similar-sized left ventricle, also deprived of the papillary muscles, had ventricular septal defect. It seems quite understandable that a ventricular septal defect should exist in all these situations, in which there is a malalignment between the muscular septum and the endocardial cushions. There are, however, cases such as our Case I, and the 3 examples reported by Van Praagh et al. (1964), in which the ventricular septum was intact. We wonder whether in these cases the other structures (muscular septum), sharing the closing of the bulboventricular foramen, would not replace the function of the endocardial 
cushions and possibly that of the conal septum too.

In all our cases, including the group $\mathrm{A}$ cases, a left ventricular cavity was found. In fact, this cavity should always be present inasmuch as it existed during a long period during embryonic development. In spite of the fact that its growth can be hindered or even stopped when certain conditions that prevent its adequate filling with blood exist (atresia of the topographically homologous atrioventricular orifice, and when there is an exaggerated displacement of the atrioventricular canal towards the bulbus cordis), the rest of it should always be present. We feel, therefore, that it should always be looked for in the myocardial area that is externally enclosed by the 2 descending coronary arteries.

The left ventricular cavity was smallest in group $A$, and largest in group $C$, in which its size was nearly normal. We feel it is very interesting to emphasize the sequence in which the left ventricle lost its papillary muscles: firstly, the anterior papillary muscle (group B cases), and, secondly, the 2 groups of papillary muscles (group A cases).

The apparently paradoxical ventricular proportions of the special case where the left ventricle is larger than the right one are considered to be due to the fact that the endocardial cushions developed more to the right than normal. Thus, the resulting tricuspid orifice was very small and the mitral one was so large that, though a portion of it was received by the right ventricle, the remaining area received by the left ventricle was still larger than the addition of the tricuspid orifice, and the portion of the mitral orifice received by the right ventricular cavity.

We would like to emphasize the great frequency with which a right ventricle receiving blood from the 2 atria gives rise to the aorta and pulmonary artery, both supported by a muscular conus (Quero Jiménez, unpublished). Five of our 7 cases of exaggerated displacement of the atrioventricular canal towards the bulbus cordis, and the case reported by Muñoz Castellanos et al. (1969), displayed this right ventricular double outlet. Similarly, most of our cases of mitral atresia (a condition in which the right ventricle also receives blood from the 2 atria) were associated with a double outlet right ventricle (Quero Jiménez, Pérez Martínez, and Moreno Granados, 1970).

Another important point to note is the rarity with which these cases of exaggerated displacement of the atrioventricular canal towards the bulbus cordis were associated with an L-loop (Quero Jiménez, unpublished), a fact that seems to be more common in cases of defective displacement of the atrioventricular canal towards the bulbus cordis (single left ventricle, double inlet left ventricle).

Cases with a common atrioventricular canal have not been included in some of the most recent contributions concerning this pathology (De la Cruz and Miller, 1968; Muñoz Castellanos et al., 1969; Liberthson et al., 1971). Nevertheless, we have included them in our study considering that the same abnormality (an excessive displacement of atrioventricular canal towards the bulbus cordis) holds true, regardless of the common or divided nature of the atrioventricular canal. The only problem would be the differential diagnosis between our cases and some forms of mitral atresia with total anomalous pulmonary venous return and very defective interatrial septum.

The electrocardiographic findings correlated very well with the ventricular proportions. Their diagnostic value was, however, very poor inasmuch as there are other conditions (mitral atresia, different forms of transposition of the great arteries, etc.) with the same ventricular proportions and, consequently, with the same electrocardiographic features. Nevertheless, when a general diagnosis of a cyanotic congenital heart defect with pulmonary ischaemia and an interventricular shunt is being considered, the presence of accentuated right ventricular hypertrophy with initial ' $q$ ' waves in $V_{3} R, V_{1}, V_{2}$, and possibly also in $\mathrm{V}_{3}$ and $\mathrm{V}_{4}$, arises, this case possibly being one in our group A or B, associated with pulmonary stenosis or atresia. Similar electrocardiographic features can be found in cases of mitral atresia associated with a severely obstructed pulmonary outflow tract.

A right ventricular contrast injection performed in the lateral projection can be very successful in showing the subaortic and subpulmonary conus, and the hypoplastic left ventricular cavity (Fig. 8) when a coexisting ventricular septal defect permits the filling of this last chamber. The same findings may be obtained in some forms of mitral atresia with double outlet right ventricle (Quero Jiménez et al., 1970). The differential diagnosis can be made by proving the patency of the left atrioventricular orifice, either by means of cardiac catheterization or angiocardiography (Quero Jiménez, unpublished) with a contrast injection in the left atrium.

\section{References}

De la Cruz, M. V., and Miller, B. L. (1968). Double-inlet left ventricle. Two pathological specimens with comments on the embryology and on its relation to single ventricle. Circulation, 37, 249.

Lev, M., Liberthson, R. R., Kirkpatrick, J. R., Eckner, F. A. O., and Arcilla, R. A. (1969). Single (primitive) ventricle. Circulation, 39, 577.

Liberthson, R. R., Paul, M. H., Muster, A. J., Arcilla, R. A., Eckner, F. A. O., and Lev, M. (197I). Straddling and displaced atrioventricular orifices and valves with primitive ventricles. Circulation, 43, 213. 
Muñoz Castellanos, L., Rodriguez Llorián, A., Martínez Ríos, A., and Espino Vela, J. (1969). Doble cámara de salida y de entrada del ventrículo derecho. Archivos del Instituto de Cardiología de México, 39, II4.

Quero Jiménez, M. Trastornos en la relación del canal atrioventricular con el tabique interventricular. Tesis doctoral, Madrid, r97I. To be published.

Quero Jiménez, M., Pérez Martínez, V., and Moreno Granados, F. (1970). Mitral atresia with double outlet right ventricle. Abstracts of papers, VIth World Congress of Cardiology, p. 256. Cardiovascular Research.
Scientific Council on Pediatric Cardiology (1970). Classification of Heart Disease in Childhood. International Society of Cardiology, The Netherlands.

Van Praagh, R., Ongley, P. A., and Swan, H. J. C. (1964). Anatomic types of single or common ventricle in man. Morphologic and geometric aspects of 60 necropsied cases. American fournal of Cardiology, 13, 367.

Requests for reprints to $M$. Quero Jiménez, Jefe Sección de Cardiologia Pediatrica, Clinica Infantil 'La Paz', Madrid, Spain. 